\section{Longitudinal and cross sectional mortality studies in injecting drug-users}

SIR - Dr Frisher et al ${ }^{1}$ have recently addressed the issue of mortality in drug injectors. They report a mortality from all causes of $0.54 \%$, which is substantially lower than that described in previous studies. Additional studies, besides those quoted by Frisher et $a l{ }^{2-6}$ showed higher mortality in drug injectors. The main difference between these studies and that of Frisher et al is that the former are all longitudinal follow up studies of drug addicts, while the latter estimates numerator and denominator separately. The authors attribute the lower rate shown in their study to an underenumeration of the denominator. We would suggest that a very likely explanation is the estimate of the numerator. The authors used the following criteria to define deaths related to drugs: (1) ICD code on death certificates; (2) reports of drug injection as the mode of transmission in deaths of subjects tested for HIV from the HIV registry; and (3) reports of drug injection in sudden deaths from the Procurator Fiscal's Office. On the basis of these data they found 51 deaths in the age group 15-40 years for the year 1989 . Over $90 \%$ of these deaths were attributed to overdose and suicide, $2 \%$ to AIDS and accidental causes, and only $9.8 \%$ to other medical causes (see table IV in the original paper). The results from other studies $(4,6-7)$ show that the proportion of deaths not directly related to drug use is relevant. In particular, the cohort study we conducted in Rome (6), following up 4200 drug injectors from 1980-88, showed that other medical causes accounted for $28 \%$ of the deaths overall. Not only do injectors seem to die from causes directly related to drug use, they have an excess risk for other causes of death, and such an excess risk could have been missed using the sources described by Frisher et al.

In conclusion, we think that mortality in drug injectors estimated by the authors cannot be considered a rate for all causes, but only an estimate of the number of deaths in drug injectors attributable to causes directly related to drug abuse. The only way to measure mortality from all causes in drug injectors is to undertake longitudinal follow up studies of defined populations.

MARINA DAVOLI CESCO FORASTIERE ELISABETTA RAPITI

CARLO A PERUCCI Epidemiology Unit, Latium Regional Health Authority, Via S Costanza, 53-00198 Roma, Italy

1 Frisher M, Bloor M, Goldberg D, et al. Mortality among injecting drug users: a critical reappraisal. $\mathcal{F}$ Epic

2 Haastrup S, Jepsen PW. Seven year follow-up of 300 young drug abusers. Acta Psychiatr Scand 1984; 70: 503-9.

3 Joe GW, Simpson DD. Mortality rates among opiate addicts in a longitudinal study. $A m \mathscr{J}$ Public Health 1987; 77: 347-8.

4 Selwyn PA, Hartel D, Wasserman W, Drucker E. Impact of the AIDS epidemic on morbidity and mortality among intravenous drug users in a New York City methadone maintenance program. Am $\mathcal{F}$ Public Health 1989; 79: 135862.

5 Engstrom A, Adamsson C, Allebeck $P$ et al. follow-up in Stockholm County, 1973-1984. Int $\mathcal{f}$ Addict 1991; 26(1): 91-106.

6 Perucci CA, Davoli M, Rapiti E, Abeni DD, Forastiere F. Mortality of intravenous drug users in Rome: a cohort study. Am $\mathcal{J}$ Public Health. 1991; 81: 1307-10.

7 Stoneburner RL, des Jarlais DC, Benezra D, et al. A larger spectrum of severe HIV-1-related disease in intravenous drug users in New York City. Science 1988; 242: 916-19.

\section{Reply}

SIR - The aims of appraising mortality in a longitudinal cohort of people who inject drugs when first entering a drug treatment programme and estimating the number of deaths over a one year period in a population of current injectors need to be clearly distinguished.

The former approach has the advantage of following up a defined population and ascertaining the cause of death of all non-survivors (whether or not they currently inject) except those lost to follow up, although as Dr Davoli and colleagues have noted elsewhere "(the longitudinal cohort) study population may be different both in character and in exposure to toxic substances from street addicts and occasional users, thus limiting the generalizability of findings. Moreover IVDUs (intravenous drug users) are a dynamic population with some current users permanently stopping drug use each year, but we could not take these changes into account because no information was available".'

It was precisely these concerns that lead us to consider an alternative method. Having estimated the number of intravenous drug users in Glasgow for $1989,{ }^{2}$ and negotiated access to the three sources of information on their mortality, it was our contention that some of the limitations of longitudinal cohort studies could be addressed by a cross sectional study. ${ }^{3}$

A total of 51 deaths were recorded in an estimated current population of 9424 (95\% CI: 6964, 11 884), giving an annual mortality of $0.54 \%$ during 1989 . This annual rate is lower than that in previous longitudinal studies and although we suggest that this may be attributable to the selected nature of reported addicts and underenumeration of the total number of injectors in some longitudinal studies, we do not propose that there is a "correct" rate appropriate to all locations and time periods.

Dr Davoli et al suggest that the rate of $0.54 \%$ "cannot be considered a rate for all causes, but only an estimate of the number of deaths in drug injectors directly attributable to drug abuse". This is clearly not the case, since table III of our paper shows that only 34 of 51 deaths were directly attributable to drug use and the remaining 17 were due to other causes including accidents, suicide by hanging, and a variety of medical condition (all of which may or may not have been influenced by injecting drug use). Anybody with clinical signs indicating injecting drug use either before or subsequent to death would almost certainly have been recorded by one or more of the three data sources. Furthermore, while the non-injecting related conditions identified by Dr Davoli et al accounted for $28 \%$ of deaths in the Italian cohort compared with $10 \%$ in Glasgow injectors, the reasons for excess mortality associated with these conditions among intravenous drug users are multifactorial. Thus, there is no logical reason why the mortality for selected conditions in different settings and time periods should be similar.

In any case, we think it extremely unlikely that more than a handful of current injectors who died from medical conditions were no detected in the cross sectional study, and even if, as seems unlikely, 10 cases were not detected the mortality would only increase to $0.65 \%$. The key point is that 51 deaths in an estimated 9424 injectors compared with about 330 deaths per year in the 370000 people aged 15-35 years in Glasgow, indicates that injecting drug use is strongly associated with an increased risk of mortality in young adults and is probably responsible for more deaths in this age group in Glasgow than any other single factor. Preliminary data for 1992 suggest that the mortality in the drug users in Glasgow has increased, with approximately 100 deaths reported by the three agencies who participated in the 1989 study.

In summary, we do not accept that "the only way to measure mortality from all causes in drug injectors is to undertake longitudinal follow up studies of defined populations". Longitudinal and cross sectional methods address related but not identical issues, the complexities of which await further investigation.

MARTIN FRISCHER and DAVID GOLDBERG

Communicable Diseases and Environmental Health (Scotland) Unit, Ruchill Hospital, Glasgow,

STEPHEN GREEN

Department of Infection and Tropical Medicine, Ruchill Hospital, Glasgow.

MICHAEL BLOOR School of Social and Administrative Studies, University of Cardiff, Cardiff. JOHN CLARK Department of Forensic Pathology,
Medico-Legal Centre, Sheffield NEIL McKEGANEY Public Health Research Unit, University of
Glasgow, Glasgow

Correspondence to: Dr M Frischer

1 Perucci C, Davoli M, Rapiti E, Abeni D, Forastiere F. Mortality of intravenous drug users in Rome: a cohort study. Am $\mathcal{J}$ Public Health Rome: a cohort st

2 Frischer $M$, Bloor $M$, Finlay $A$, et al. A new method of estimating prevalence of injecting method of estimating prevalence of injecting a Scottish city. Int ₹ Epidemiol 1991; 20: 997a Sco

3 Frischer M, Bloor M, Goldberg D, Clark C Green S, McKeganey N. Mortality among injecting drug users: a critical reappraisal. Epidemiol Community Health 1993; 47: 59-63.

\section{NOTICES}

New Epidemics in Occupational Health Helsinki, Finland, 16-19 May 1994. For further information: Symposium Secretariat, International Symposium on New Epidemics in Occupational Health, Finnish Institute of Occupational Health, Ms Suvi Lehtinen, Topeliuksenkatu 41 a A, FIN-00250 Helsinki, Finland; tel: + 358047471 ; fax: + 358 04747548 . 